\title{
Identification of critical genes and biological signaling for metformin treated liver cancer
}

Tingting Zhang, Hongmei Guo, Letian Wang, Mengyao Wang, Hanming Gu ${ }^{1}$

${ }^{1}$ SHU-UTS SILC School, Shanghai University, Shanghai, China

"Corresponding author: Hanming Gu, SHU-UTS SILC School, Shanghai University, Shanghai, China

laygmp@gmail.com 


\section{Abstract}

Liver cancer is a leading source of cancer-related mortality in the world. A number of studies have shown the correlation of metformin treatment with a decrease in cancer risk. However, the relevant molecules and mechanisms are not clear during the treatment. In this study, our aim is to identify the significant molecules and signaling pathways in the treatment of metformin in liver cancer cells by analyzing the RNA sequence. The GSE190076 dataset was created by performing the Illumina NovaSeq 6000 (Homo sapiens). The KEGG and GO analyses indicated that DNA synthesis and cell cycle are the main processes during the treatment of metformin. Moreover, we determined numerous genes including RRM2, CDC6, CDC45, UHRF1, ASF1B, ZWINT, PCNA, ASPM, MYC, and TK1 by using the PPI network. Therefore, our study may guide the clinical work on the treatment of liver cancer by using metformin.

\section{Introduction}

Primary liver cancer is an aggressive tumor that is one of the most common cancers in the world ${ }^{1}$. In the United States, the annual incidence of liver cancer is increasing despite the advanced treatment, and liver cancer remains one of the most difficult cancers to cure $^{2}$. There are various treatments for liver cancer, which are selected according to the complex interplay of tumor stage and patient's status ${ }^{3}$.

Metformin is an essential drug for the treatment of diabetes, which is the most commonly used oral drug and is recommended as the first-line therapy for T2D patients ${ }^{4}$. Besides diabetes, metformin is also used in polycystic ovary diseases, diabetic nephropathy, and cardiovascular complications ${ }^{5}$. Most importantly, metformin indicated the anti-cancer functions through both indirect and direct effects ${ }^{6}$. The indirect mechanisms contribute to the regulation of blood glucose and insulin, which could affect cancer cell survival ${ }^{7}$. Metformin directly inhibits the NF-kB activity to further activate the immune response to cancer cells ${ }^{8}$. For example, metformin enhanced the effectiveness of the anti-cancer vaccine that was regulated by the activation of T cells ${ }^{9}$.

Here, our present studies determined the DEGs and signaling pathways of metformin in liver cancer by analyzing the RNA-seq data. We figured out several functional DEGs and processes and created the protein-protein interaction (PPI) network. It is possible 
that our understanding of the anti-cancer properties of metformin will result in advances in the treatment of liver cancer.

\section{Methods}

Data resources

The data (GSE190076) was created by using Illumina NovaSeq 6000 (Homo sapiens) (Hebei University, Number 180, Wusi east street, Baoding, Hebei Province, China). The analyzed dataset includes three groups of control liver cancer cells and three groups of liver cancer cells treated by metformin.

Data acquisition and preprocessing

The data were processed by the $R$ package as described ${ }^{10-14}$. A classical t-test was performed to identify DEGs with $\mathrm{P}<0.01$ and fold change $\geq 1$ as being statistically significant.

The Kyoto Encyclopedia of Genes and Genomes (KEGG) and Gene Ontology (GO) analyses

The KEGG and GO analyses were performed from the R package (clusterProfiler) and Reactome (https://reactome.org/). We set the $\mathrm{P}<.05$ and gene counts $>10$ as the statistically significant cutoff.

Protein-protein interaction (PPI) analysis

The PPI was constructed by using the Molecular Complex Detection (MCODE). The biological processes analysis was performed by Reactome, and $\mathrm{P}<0.05$ was considered as the statistically significant cutoff.

\section{Results}

\section{Identification of DEGs of metformin treated liver cancer cells}

To understand the mechanism of the effects of metformin on liver cancers, we analyzed the RNA-seq data from the metformin treated liver cancer cells. A total of 125 genes were identified with the threshold of $P<0.001$. The top up-and down-regulated genes in 
metformin treated liver cancer cells were identified by the heatmap and volcano plot (Figure 1). The top ten DEGs were listed in Table 1.

\section{Enrichment analysis of DEGs in the metformin treated liver cancer cells}

To further understand the potential biological functions of the DEGs, we introduced the KEGG and GO analyses (Figure 2). The significant items of KEGG were selected, including "Cell cycle", "Cellular senescence", "TGF-beta signaling pathway", "DNA replication", and "Fanconi anemia pathway", and "Mismatch repair". We also identified the top ten biological processes of GO, including "Regulation of mitotic cell cycle", "Nuclear division", "Chromosome segregation", "Negative regulation of cell cycle", "DNA replication", "Nuclear chromosome segregation", "Sister chromatid segregation", "Mitotic sister chromatid segregation", "DNA-dependent DNA replication", and "Cell cycle checkpoint signaling". We then identified the top ten cellular components of GO, including "chromosomal region", "spindle", "condensed chromosome", "chromosome, centromeric region", "condensed chromosome, centromeric region", "mitotic spindle", "kinetochore", "spindle midzone", "DNA replication preinitiation complex", and "CMG complex". We identified the top ten molecular functions of GO, including "ubiquitin-like protein transferase activity", "ubiquitin-like protein ligase activity", "catalytic activity, acting on DNA", "histone binding", "helicase activity", "single-stranded DNA binding", "ATP-dependent activity, acting on DNA", "DNA helicase activity", "single-stranded DNA helicase activity", and "DNA replication origin binding".

\section{Construction of PPI network in the metformin treated liver cancer cells}

To further identify the potential relationship of the DEGs, we constructed the PPI network by the String and Cytoscope software. The PPI network was created by using 116 nodes and 164 edges (combined score > 0.4). The top ten genes were selected with the highest degree scores (Table 2). The String network and top clusters were shown in Figure 3. We further analyzed the PPI genes and DEGs by Reactome map (Figure 4) and selected the top ten potential biological functions including "G1/SSpecific Transcription", "Mitotic G1 phase and G1/S transition”, "G1/S Transition”, "Cell Cycle, Mitotic", "Cell Cycle", "Transcription of E2F targets under negative control by DREAM complex", "Transcriptional Regulation by E2F6", "G0 and Early G1", and "Activation of ATR in response to replication stress" (Supplemental Table S1). 


\section{Discussion}

Metformin can inhibit hepatic gluconeogenesis and promote glucose uptake in muscles, and it also can improve the prognosis of cancer patients and block the progression of tumor ${ }^{6,15}$. Thus, metformin is currently being investigated for new anti-cancer drugs ${ }^{16}$. Metformin is a key regulator in liver cancer by mediating the DNA replication and cell cycle through the KEGG and GO analyses. Interestingly, Sung-Hee Kim et al found metformin enhances chemo-sensitivity by decreasing DNA replication proteins in colorectal cancer cell ${ }^{17}$. Krisztina Kisfalvi et al found metformin disturbs the relationship between $G$ protein-coupled receptor and insulin receptor signaling systems to further prevent cancer growth ${ }^{18}$. As key signaling regulators, GPCR and RGS proteins are involved in a variety of human diseases including cancer, arthritis, bone diseases, and heart diseases ${ }^{19-29}$. It was found that low doses of metformin inhibited the DNA synthesis and tumor growth by insulin and GPCR agonists ${ }^{18}$. James Sinnett-Smith et al found metformin can inhibit the activation of mTORC1, DNA synthesis in pancreatic cancer by affecting the AMPK signaling ${ }^{30}$. Metformin is capable to inhibit the proliferation of multiple myeloma cells by the inhibition of G0/G1 cell cycle arrest but not apoptosis $^{31}$. Xiaojia Zhou also found metformin restrains the cell proliferation in SKM-1 cells through AMPK-regulated cell cycle arrest ${ }^{32}$. The study by Takuma Yamashita showed metformin prohibits the proliferation in gallbladder adenocarcinoma cell lines including NOZ, TGBC14TKB, and TGBC24TKB, and inhibits the cell cycle ${ }^{33}$.

Besides the important biological processes, we also identified a number of key genes that involve in the treatment of liver cancer with metformin. Yueyue Yang et al found BRM2 is a liver cancer biomarker that indicates specifically increased levels in liver cancer and restraints ferroptosis by triggering GSH synthesis ${ }^{34}$. The high expression of RRM2 was found in $81 \%$ of patients with liver cancer and the expression of RRM2 was associated with viral etiology and liver cirrhosis, which may be a biological marker for poor prognosis of liver cancer ${ }^{35}$. CDC6 was identified as a therapeutic target of miR-215 in liver cancer ${ }^{36}$. Moreover, CDC6 is an essential player for DNA replication, which is related to the risk for liver cancer ${ }^{37}$. The circadian clocks and downstream targets are related to a variety of physiological and pathophysiological processes such as cell 
proliferation, cell differentiation, cell metabolism, immune, and secretion ${ }^{38-47}$. Jorge Fung-Uceda et al found the clock component TOC1 can inhibit DNA replication by binding the CDC6 promoter ${ }^{48}$. Bioinformatic analysis showed the CDC45 gene is closely associated with liver cancer and patient outcomes ${ }^{49}$. Sheng-Ming $\mathrm{Wu}$ et al found the knockdown of UHRF1 can inhibit the progression of liver cancer ${ }^{50}$. ASF1A is considered as a prognostic marker, which involves in the progression and development of specific cancers $^{51}$. ZWINT plays key roles in the mitotic checkpoint, which can predict the pathogenesis and prognosis of liver cancer ${ }^{52}$. PCNA is identified as a potential marker for early hepatocellular carcinoma ${ }^{53}$. ASPM is a biological marker for vascular invasion and poor prognosis of liver cancer ${ }^{54}$. Kyu Yun Jang et al found SITR1 and MYC drive liver tumor cell survival and predict liver cancer ${ }^{55}$. Serological TK1 is a critical proliferation biomarker for the early discovery of pre-malignancies ${ }^{56}$.

In conclusion, our study showed the significant impact of metformin in liver cancer. The DNA replication and cell cycle are the major signaling pathways involved in the treatment of liver cancer with metformin. Therefore, this study may be beneficial in the treatment of hepatocellular carcinoma.

\section{Author Contributions}

Tingting Zhang, Hongmei Guo, Letian Wang, Mengyao Wang: Methodology and Writing. Hanming Gu: Conceptualization, Writing- Reviewing and Editing.

\section{Funding}

This work was not supported by any funding.

\section{Declarations of interest}

There is no conflict of interest to declare. 
A

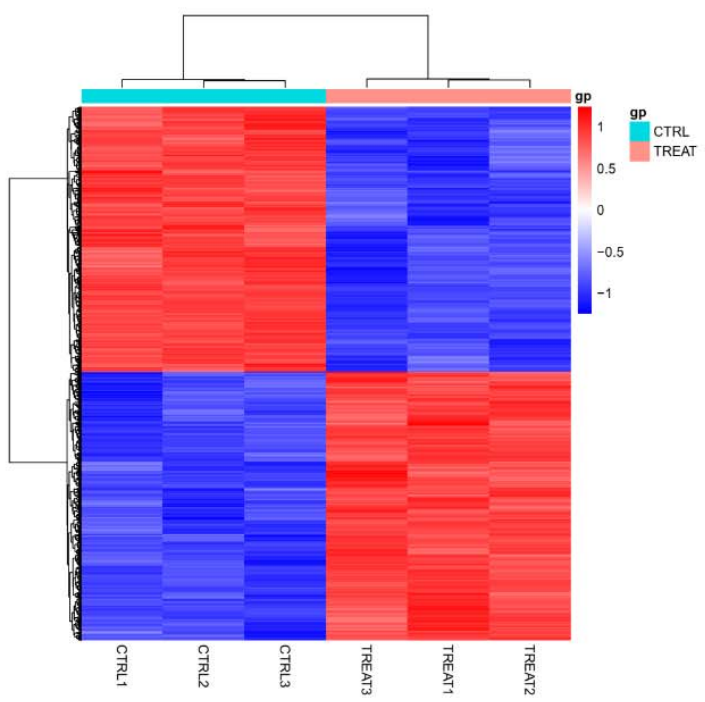

B

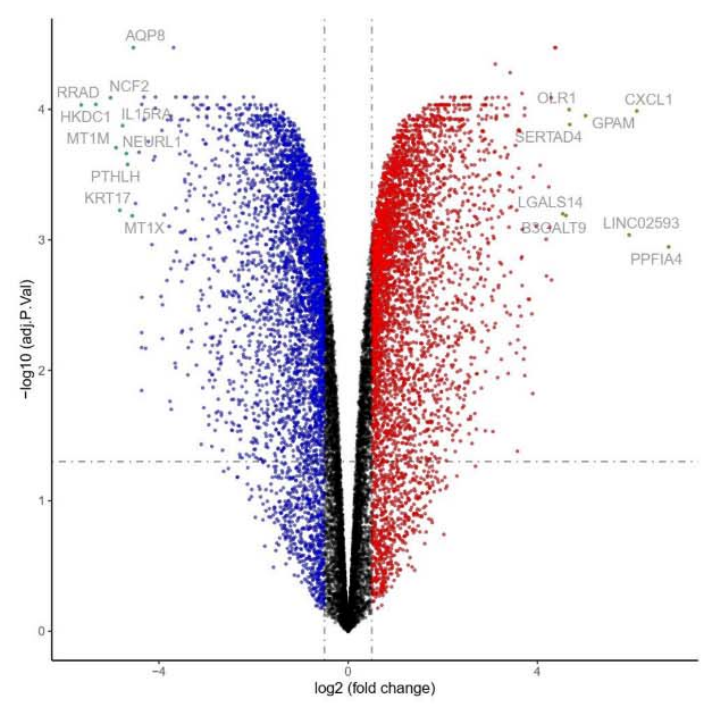

Figure 1. Heatmap and volcano plot were obtained between the control (CTRL) and metformin treated (TREAT) liver cancer cells

(A) Heatmap of significant DEGs. Significant DEGs $(P<0.01)$ were used to create the heatmap.

(B) Volcano plot for DEGs between the control and metformin treated liver cancer cells. The most significantly changed genes are highlighted by grey dots. 

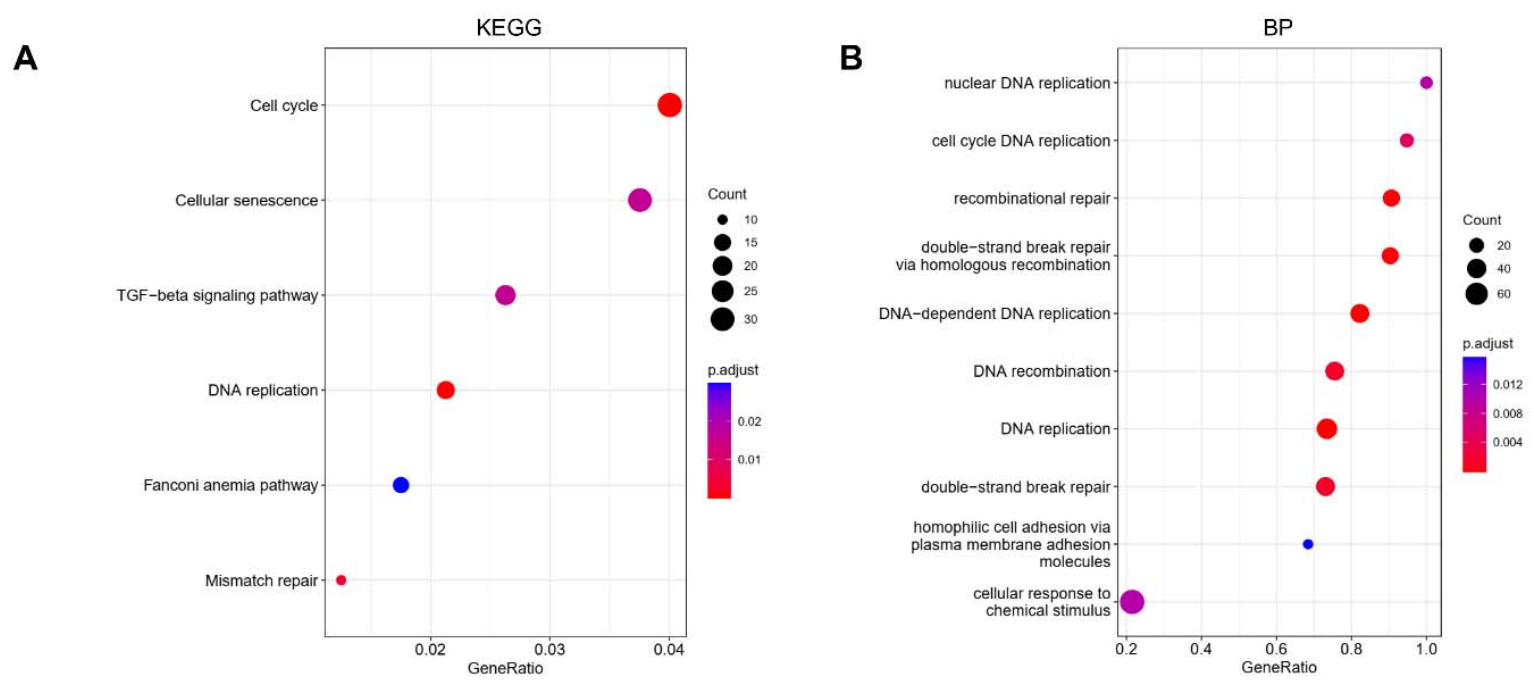

C
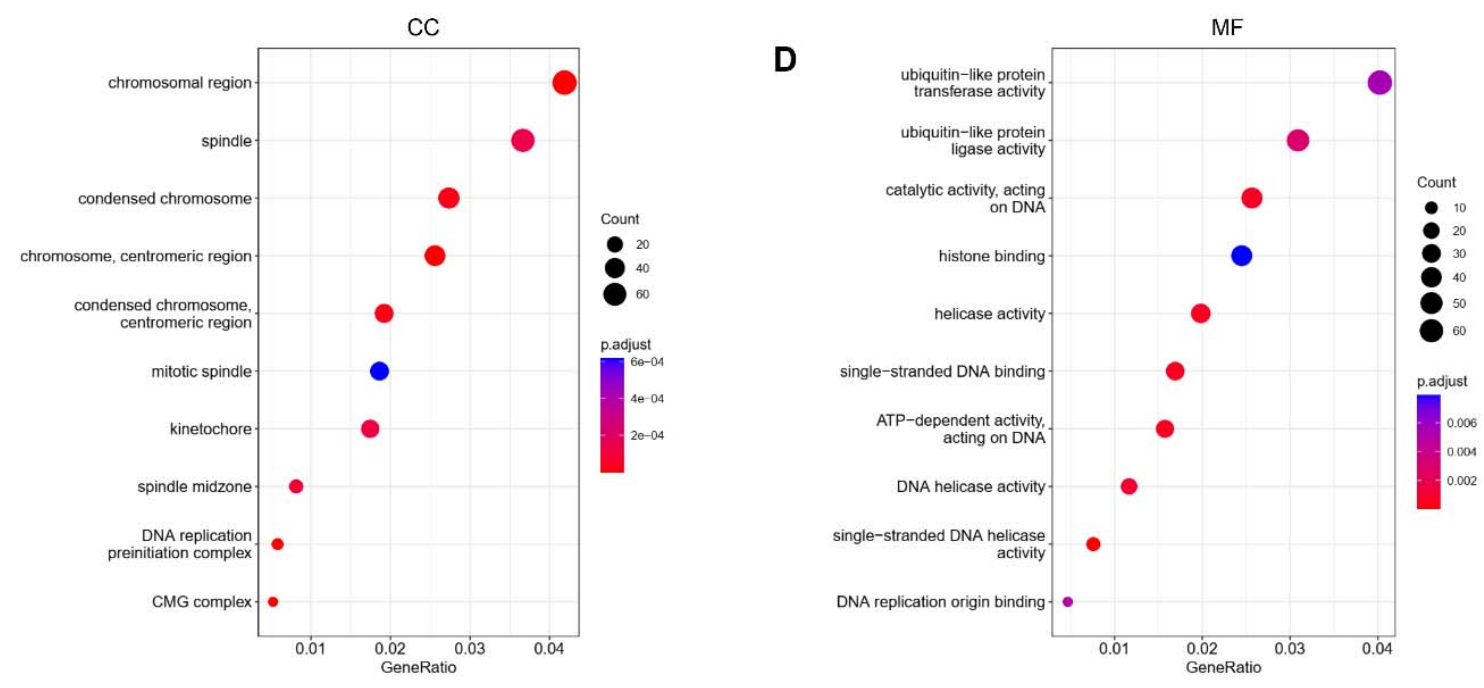

Figure 2. KEGG and GO analyses of DEGs between the control and metformin treated liver cancer cells

(A) KEGG analysis, (B) Biological processes, (C) Cellular components, (D) Molecular functions. 

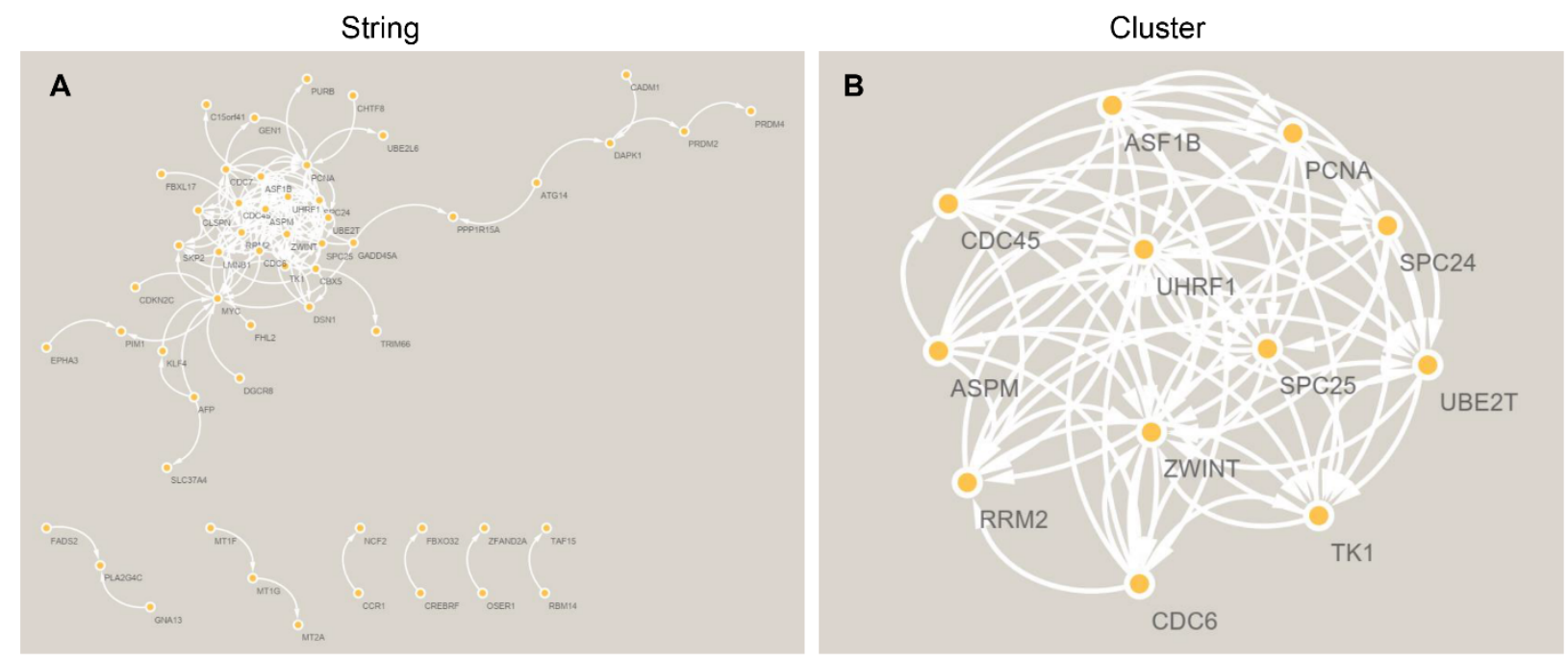

Figure 3. The String and PPI network analyses of DEGs between the control and metformin treated liver cancer cells

String (A) and the first cluster (B) were constructed by MCODE and Cytoscape. 
bioRxiv preprint doi: https://doi.org/10.1101/2021.12 29.474467. this version posted December 30,2021 . The copyright holder for this preprint (which was not certified by peer review) is the author/funder, who has granted bioRxiv a license to display the preprint in perpetuity. It is made available under aCC-BY-NC-ND 4.0 International license.

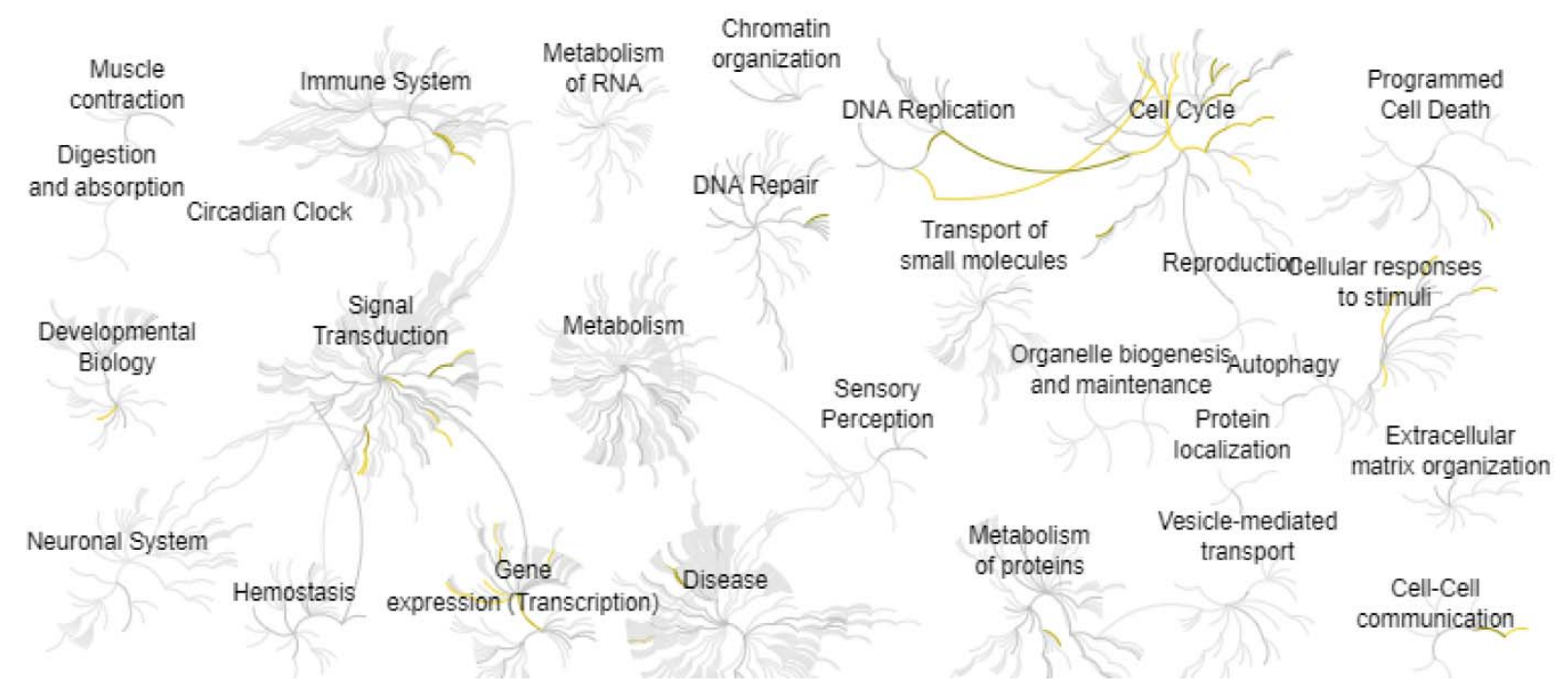

Figure 4. Reactome map representation of the significant biological processes between the control and metformin treated liver cancer cells 


\begin{tabular}{llll}
\multicolumn{1}{l}{ Table 1 } & & \\
\hline Entrez gene & Gene symbol & Fold-change & Regulation \\
\hline \multicolumn{1}{l}{ Top 10 down-regulated DEGs } & & \\
6236 & RRAD & -5.641311351 & Down \\
80201 & HKDC1 & -5.331256314 & Down \\
4688 & NCF2 & -5.019051335 & Down \\
343 & AQP8 & -4.538374629 & Down \\
2331 & FMOD & -4.360346053 & Down \\
119395 & CALHM3 & -4.314311307 & Down \\
9229 & DLGAP1 & -4.076112 & Down \\
5649 & RELN & -4.068611599 & Down \\
153222 & CREBRF & -3.688866916 & Down \\
4495 & MT1G & -3.639888941 & Down \\
Top 10 up-regulated DEGs & & \\
4973 & OLR1 & 4.670169784 & up \\
374393 & FAM111B & 4.38801419 & up \\
4091 & SMAD6 & 4.369002101 & up \\
29128 & UHRF1 & 4.290715153 & up \\
6241 & RRM2 & 3.73058798 & up \\
9502 & XAGE2 & 3.67535914 & up \\
9415 & FADS2 & 3.423215343 & up \\
65263 & PYCR3 & 3.392965269 & up \\
54058 & C210rf58 & 3.332096934 & up \\
147011 & PROCA1 & 3.285038179 & up \\
\hline
\end{tabular}


Table 2. Top ten genes demonstrated by connectivity degree in the PPI network

\begin{tabular}{lll}
\hline Gene symbol & Gene title & Degree \\
\hline RRM2 & Ribonucleotide Reductase Regulatory & 18 \\
& Subunit M2 & 17 \\
CDC6 & Cell Division Cycle 6 & 17 \\
CDC45 & Cell Division Cycle 45 & 16 \\
UHRF1 & Ubiquitin Like With PHD And Ring Finger & 16 \\
& $\begin{array}{l}\text { Domains 1 } \\
\text { ASF1B }\end{array}$ & Anti-Silencing Function 1B Histone \\
& Chaperone & 15 \\
ZWINT & ZW10 Interacting Kinetochore Protein & 15 \\
PCNA & Proliferating Cell Nuclear Antigen & 15 \\
ASPM & Assembly Factor For Spindle Microtubules & 14 \\
MYC & MYC Proto-Oncogene, Bhlh Transcription & 13 \\
& Factor & 12 \\
TK1 & Thymidine Kinase 1 & 13 \\
\hline
\end{tabular}




\section{References}

[1] Yang JD, Hainaut P, Gores GJ, Amadou A, Plymoth A, Roberts LR: A global view of hepatocellular carcinoma: trends, risk, prevention and management. Nat Rev Gastroenterol Hepatol 2019, 16:589-604.

[2] Liu CY, Chen KF, Chen PJ: Treatment of Liver Cancer. Cold Spring Harb Perspect Med 2015, 5:a021535.

[3] Lurje I, Czigany Z, Bednarsch J, Roderburg C, Isfort P, Neumann UP, Lurje G: Treatment Strategies for Hepatocellular Carcinoma (-) a Multidisciplinary Approach. Int J Mol Sci 2019, 20.

[4] Irons BK, Minze MG: Drug treatment of type 2 diabetes mellitus in patients for whom metformin is contraindicated. Diabetes Metab Syndr Obes 2014, 7:15-24.

[5] Lashen $\mathrm{H}$ : Role of metformin in the management of polycystic ovary syndrome. Ther Adv Endocrinol Metab 2010, 1:117-28.

[6] Saraei P, Asadi I, Kakar MA, Moradi-Kor N: The beneficial effects of metformin on cancer prevention and therapy: a comprehensive review of recent advances. Cancer Manag Res 2019, 11:3295-313.

[7] Ryu TY, Park J, Scherer PE: Hyperglycemia as a risk factor for cancer progression. Diabetes Metab J 2014, 38:330-6.

[8] Hirsch HA, Iliopoulos D, Struhl K: Metformin inhibits the inflammatory response associated with cellular transformation and cancer stem cell growth. Proc Natl Acad Sci U S A 2013, 110:972-7.

[9] Verdura S, Cuyas E, Martin-Castillo B, Menendez JA: Metformin as an archetype immuno-metabolic adjuvant for cancer immunotherapy. Oncoimmunology 2019, 8:e1633235.

[10] Gu H: Identification of biomarkers and pathways of mouse embryonic fibroblasts with the dysfunction of mitochondrial DNA. bioRxiv 2021:2021.04.05.438453.

[11] Zhang M, Wang J, Gu H: Identification of biological processes and signaling pathways in the stretched nucleus pulposus cells. bioRxiv 2021:2021.11.23.469730.

[12] Yuan G: Identification of biomarkers and pathways of mitochondria in sepsis patients. bioRxiv 2021:2021.03.29.437586.

[13] Jing L, Letian W, Hanming G: Identification of driver genes and biological signaling for alcoholic myopathy. Research Square 2021.

[14] Yu G, Wang LG, Han Y, He QY: clusterProfiler: an R package for comparing biological themes among gene clusters. OMICS 2012, 16:284-7.

[15] Luengo A, Sullivan LB, Heiden MG: Understanding the complex-l-ty of metformin action: limiting mitochondrial respiration to improve cancer therapy. BMC Biol 2014, 12:82.

[16] Luo X, Chen X, Wang L, Yang B, Cai S: Metformin Adjunct With Antineoplastic Agents for the Treatment of Lung Cancer: A Meta-Analysis of Randomized Controlled Trials and Observational Cohort Studies. Front Pharmacol 2021, 12:639016.

[17] Kim SH, Kim SC, Ku JL: Metformin increases chemo-sensitivity via gene downregulation encoding DNA replication proteins in 5-Fu resistant colorectal cancer cells. Oncotarget 2017, 8:56546-57.

[18] Kisfalvi K, Eibl G, Sinnett-Smith J, Rozengurt E: Metformin disrupts crosstalk between G proteincoupled receptor and insulin receptor signaling systems and inhibits pancreatic cancer growth. Cancer Res 2009, 69:6539-45.

[19] Yuan G, Huang Y, Yang S-t, Ng A, Yang S: RGS12 inhibits the progression and metastasis of multiple myeloma by driving M1 macrophage polarization and activation in the bone marrow microenvironment. Cancer Commun, n/a.

[20] Fu C, Yuan G, Yang ST, Zhang D, Yang S: RGS12 Represses Oral Cancer via the Phosphorylation and SUMOylation of PTEN. J Dent Res 2020:22034520972095.

[21] Yuan G, Yang S, Gautam M, Luo W, Yang S: Macrophage regulator of G-protein signaling 12 contributes to inflammatory pain hypersensitivity. Ann Transl Med 2021, 9:448. 
[22] Montero-Melendez T, Nagano A, Chelala C, Filer A, Buckley CD, Perretti M: Therapeutic senescence via GPCR activation in synovial fibroblasts facilitates resolution of arthritis. Nat Commun 2020, 11:745.

[23] Yuan G, Yang S, Yang S: Macrophage RGS12 contributes to osteoarthritis pathogenesis through enhancing the ubiquitination. Genes \& Diseases 2021.

[24] Yuan G, Fu C, Yang ST, Yuh DY, Hajishengallis G, Yang S: RGS12 Drives Macrophage Activation and Osteoclastogenesis in Periodontitis. J Dent Res 2021:220345211045303.

[25] Pavlos NJ, Friedman PA: GPCR Signaling and Trafficking: The Long and Short of It. Trends Endocrinol Metab 2017, 28:213-26.

[26] Yuan G, Yang S, Yang S, Ng A, Oursler MJ: RGS12 is a critical proinflammatory factor in the pathogenesis of inflammatory arthritis via acting in Cox2-RGS12-NF kappa B pathway activation loop. J Bone Miner Res: WILEY 111 RIVER ST, HOBOKEN 07030-5774, NJ USA, 2019. pp. 147-.

[27] Yuan G, Yang S, Liu M, Yang S: RGS12 is required for the maintenance of mitochondrial function during skeletal development. Cell Discov 2020, 6:59.

[28] Bohinc BN, Gesty-Palmer D: Arrestins in bone. Prog Mol Biol Transl Sci 2013, 118:335-58.

[29] Yuan G, Yang S, Ng A, Fu C, Oursler MJ, Xing L, Yang S: RGS12 Is a Novel Critical NF-kappaB Activator in Inflammatory Arthritis. iScience 2020, 23:101172.

[30] Sinnett-Smith J, Kisfalvi K, Kui R, Rozengurt E: Metformin inhibition of mTORC1 activation, DNA synthesis and proliferation in pancreatic cancer cells: dependence on glucose concentration and role of AMPK. Biochem Biophys Res Commun 2013, 430:352-7.

[31] Wang Y, Xu W, Yan Z, Zhao W, Mi J, Li J, Yan H: Metformin induces autophagy and G0/G1 phase cell cycle arrest in myeloma by targeting the AMPK/mTORC1 and mTORC2 pathways. J Exp Clin Cancer Res 2018, 37:63.

[32] Zhou X, Kuang Y, Liang S, Wang L: Metformin inhibits cell proliferation in SKM-1 cells via AMPKmediated cell cycle arrest. J Pharmacol Sci 2019, 141:146-52.

[33] Yamashita T, Kato K, Fujihara S, Iwama H, Morishita A, Yamana H, Kobayashi K, Kamada H, Chiyo T, Kobara H, Tsutsui K, Okano K, Suzuki Y, Masaki T: Anti-diabetic drug metformin inhibits cell proliferation and tumor growth in gallbladder cancer via G0/G1 cell cycle arrest. Anticancer Drugs 2020, 31:231-40.

[34] Yang Y, Lin J, Guo S, Xue X, Wang Y, Qiu S, Cui J, Ma L, Zhang X, Wang J: RRM2 protects against ferroptosis and is a tumor biomarker for liver cancer. Cancer Cell Int 2020, 20:587.

[35] Lee B, Ha SY, Song DH, Lee HW, Cho SY, Park CK: High expression of ribonucleotide reductase subunit M2 correlates with poor prognosis of hepatocellular carcinoma. Gut Liver 2014, 8:662-8.

[36] Xu H, Huang J, Hua S, Liang L, He X, Zhan M, Lu L, Chu J: Interactome analysis of gene expression profiles identifies CDC6 as a potential therapeutic target modified by miR-215-5p in hepatocellular carcinoma. Int J Med Sci 2020, 17:2926-40.

[37] Xiong XD, Fang JH, Qiu FE, Zhao J, Cheng J, Yuan Y, Li SP, Zhuang SM: A novel functional polymorphism in the Cdc6 promoter is associated with the risk for hepatocellular carcinoma. Mutat Res 2008, 643:70-4.

[38] Xu L, Cheng Q, Hua B, Cai T, Lin J, Yuan G, Yan Z, Li X, Sun N, Lu C, Qian R: Circadian gene Clock regulates mitochondrial morphology and functions by posttranscriptional way. bioRxiv 2018:365452.

[39] Yuan G, Hua B, Cai T, Xu L, Li E, Huang Y, Sun N, Yan Z, Lu C, Qian R: Clock mediates liver senescence by controlling ER stress. Aging 2017, 9:2647-65.

[40] Zhu Z, Hua B, Xu L, Yuan G, Li E, Li X, Sun N, Yan Z, Lu C, Qian R: CLOCK promotes 3T3-L1 cell proliferation via Wnt signaling. IUBMB Life 2016, 68:557-68.

[41] Yuan G, Hua B, Yang Y, Xu L, Cai T, Sun N, Yan Z, Lu C, Qian R: The Circadian Gene Clock Regulates Bone Formation Via PDIA3. J Bone Miner Res 2017, 32:861-71.

[42] Fan XF, Wang XR, Yuan GS, Wu DH, Hu LG, Xue F, Gong YS: [Effect of safflower injection on endoplasmic reticulum stress-induced apoptosts in rats with hypoxic pulmonary hypertension]. Zhongguo Ying Yong Sheng Li Xue Za Zhi 2012, 28:561-7. 
[43] Zhu Z, Hua B, Shang Z, Yuan G, Xu L, Li E, Li X, Sun N, Yan Z, Qian R, Lu C: Altered Clock and Lipid Metabolism-Related Genes in Atherosclerotic Mice Kept with Abnormal Lighting Condition. Biomed Res Int 2016, 2016:5438589.

[44] Yuan G, Xu L, Cai T, Hua B, Sun N, Yan Z, Lu C, Qian R: Clock mutant promotes osteoarthritis by inhibiting the acetylation of NFkappaB. Osteoarthritis Cartilage 2019, 27:922-31.

[45] Mao SZ, Fan XF, Xue F, Chen R, Chen XY, Yuan GS, Hu LG, Liu SF, Gong YS: Intermedin modulates hypoxic pulmonary vascular remodeling by inhibiting pulmonary artery smooth muscle cell proliferation. Pulm Pharmacol Ther 2014, 27:1-9.

[46] Zhu Z, Xu L, Cai T, Yuan G, Sun N, Lu C, Qian R: Clock represses preadipocytes adipogenesis via GILZ. J Cell Physiol 2018, 233:6028-40.

[47] Cai T, Hua B, Luo D, Xu L, Cheng Q, Yuan G, Yan Z, Sun N, Hua L, Lu C: The circadian protein CLOCK regulates cell metabolism via the mitochondrial carrier SLC25A10. Biochim Biophys Acta Mol Cell Res 2019, 1866:1310-21.

[48] Fung-Uceda J, Lee K, Seo PJ, Polyn S, De Veylder L, Mas P: The Circadian Clock Sets the Time of DNA Replication Licensing to Regulate Growth in Arabidopsis. Dev Cell 2018, 45:101-13 e4.

[49] Lu HP, Du XF, Li JD, Huang SN, He RQ, Wu HY, Li MF, Wu WZ, Chen JT, Mo WJ, Chen G: Expression of Cell Division Cycle Protein 45 in Tissue Microarrays and the CDC45 Gene by Bioinformatics Analysis in Human Hepatocellular Carcinoma and Patient Outcomes. Med Sci Monit 2021, 27:e928800.

[50] Wu SM, Cheng WL, Liao CJ, Chi HC, Lin YH, Tseng YH, Tsai CY, Chen CY, Lin SL, Chen WJ, Yeh YH, Huang $\mathrm{CY}$, Chen MH, Yeh YC, Lin KH: Negative modulation of the epigenetic regulator, UHRF1, by thyroid hormone receptors suppresses liver cancer cell growth. Int J Cancer 2015, 137:37-49.

[51] Hu X, Zhu H, Zhang X, He X, Xu X: Comprehensive analysis of pan-cancer reveals potential of ASF1B as a prognostic and immunological biomarker. Cancer Med 2021, 10:6897-916.

[52] Zhu W, Zhang Q, Liu M, Yan M, Chu X, Li Y: Identification of DNA repair-related genes predicting pathogenesis and prognosis for liver cancer. Cancer Cell Int 2021, 21:81.

[53] Ma S, Yang J, Li J, Song J: The clinical utility of the proliferating cell nuclear antigen expression in patients with hepatocellular carcinoma. Tumour Biol 2016, 37:7405-12.

[54] Zhang H, Yang X, Zhu L, Li Z, Zuo P, Wang P, Feng J, Mi Y, Zhang C, Xu Y, Jin G, Zhang J, Ye H: ASPM promotes hepatocellular carcinoma progression by activating Wnt/beta-catenin signaling through antagonizing autophagy-mediated Dvl2 degradation. FEBS Open Bio 2021, 11:2784-99.

[55] Jang KY, Noh SJ, Lehwald N, Tao GZ, Bellovin DI, Park HS, Moon WS, Felsher DW, Sylvester KG: SIRT1 and c-Myc promote liver tumor cell survival and predict poor survival of human hepatocellular carcinomas. PLoS ONE 2012, 7:e45119.

[56] Wang Y, Jiang X, Wang S, Yu H, Zhang T, Xu S, Li W, He E, Skog S: Serological TK1 predict pre-cancer in routine health screenings of 56,178 people. Cancer Biomark 2018, 22:237-47. 